\title{
Aerobic capacity and anaerobic threshold of wheelchair basketball players
}

\author{
A Rotstein, M Sagiv, D Ben-Sira, G Werber, J Hutzler, H Annenburg
}

Sports Medicine and Rehabilitation Division, The Zinman College of Physical Education, Wingate, 42902, Israel.

This study evaluated the aerobic capacity and anaerobic threshold of national level Israeli wheelchair basketball players. Subjects were tested working on a wheelchair rolling on a motor driven treadmill and on an arm cycle ergometer. Metabolic and cardiopulmunary parameters were measured during graded maximal exercise tests. Blood lactic acid (LA) concentration was measured in the intervals between loads during the test on the wheelchair. Heart rate (HR) and $\%$ heart rate reserve (\% HRR) corresponding to the anaerobic threshold ( $4 \mathrm{mM}$ blood LA) were evalulated while working on the wheelchair rolling on a motor driven treadmill. While working on the wheelchair the following peak exercise values were obtained: $\mathrm{Vo}_{2}=24.7 \mathrm{ml} \mathrm{kg} / \mathrm{min}, \mathrm{VE}=92.09 \mathrm{l} / \mathrm{min} \mathrm{HR}=181.5 \mathrm{~b} /$ $\min$ and $\mathrm{R}=1.22$. Values corresponding to the anaerobic threshold were found to be, $\mathrm{HR}=139 \mathrm{~b} / \mathrm{min}$ and $\% \mathrm{HRR}=57.02$. Low correlations were obtained between peak exercise $\mathrm{Vo}_{2}$ and $\mathrm{VE}$ measured while working on the wheelchair and those measured with arm cycle ergometer $(r=0.57 p=0.137$ and $r=0.4$ $p=0.233$ respectively). As athletes, subjects in the present study may be classified as having a low aerobic capacity and anaerobic threshold. It is also concluded that the ergometer type may have an important influence on test results.

Keywords: wheelchair dependent; aerobic capacity; anaerobic threshold; basketball players.

\section{Introduction}

Regular wheelchair locomotion requires relatively low energy output and results in low physiological stress for the cardipulmonary system. ${ }^{1,2}$ As a result wheelchairdependent subjects usually have a low work capacity with higher than optimal percent body fat. ${ }^{3}$

Evidence has also been found of a higher prevalence of hypertension, cardiovascular insufficiency and diabetes in nonactive wheelchair users. ${ }^{4}$ Upper body physical training is important in maintaining cardiovascular fitness in this population. ${ }^{5,6}$

In recent years wheelchair sports have gained increasing acceptance and popularity which has led to an increase in specific training programmes of wheelchair-dependent athletes. ${ }^{7}$ Aerobic and anaerobic capacities have been reported for various wheelchair-dependent populations using various protocols and ergometers. Anerobic thresh- old is an important measure of endurance. When it is evaluated during the performance of a specific sport activity, for example working in a wheelchair, it may be very useful in planning training intensities for that acitivity.

The purpose of the present investigation was to evaluate the maximal aerobic capacity and anaerobic threshold of wheelchairdependent Israeli basketball players.

\section{Methods}

Eight subjects were tested: all were wheelchair-dependent basketball players of the Israeli national team. Table I summarises anthropometric characteristics and level of disablility. Subjects reported to the laboratory three times within 2 weeks.

Anaerobic threshold evaluation was performed during the first session. Subjects 
Table I Anthropometric parameters of subjects

\begin{tabular}{lccccl}
\hline Subject & $\begin{array}{c}\text { Age } \\
\text { (years) }\end{array}$ & $\begin{array}{c}\text { Weight } \\
(\mathrm{kg})\end{array}$ & \% Fat & $\begin{array}{c}\text { Basketball } \\
\text { class }\end{array}$ & Disability level \\
\hline 1 & 19 & 60 & 9.7 & 1.5 & Spinal injury complete T7 \\
2 & 26 & 70 & 4.5 & 1.0 & Spinal injury complete T4 \\
3 & 24 & 59 & 2.4 & 2.5 & Osteogenesis imperfecta \\
4 & 38 & 62 & 10.8 & 4.0 & Above knee amputee \\
5 & 25 & 74 & 7.0 & 4.5 & Below knee amputee \\
6 & 36 & 98 & 28.3 & 3.0 & Polio lesion of both legs \\
7 & 48 & 70 & 14.7 & 2.0 & Spinal injury complete T10 \\
8 & 34 & 116 & 30.2 & 4.0 & Spinal injury incomplete L5 \\
Mean & 31.2 & 76.1 & 16.1 & & \\
S.D & 9.4 & 20.3 & 10.0 & & \\
\hline
\end{tabular}

performed a graded exercise test seated in a wheelchair rolling on a motor driven treadmill (Woodway). Each subject used his own wheelchair. The exercise test was performed at a constant speed (4-5 mph), the test was started with $0 \%$ elevation which was increased by $1.5 \%$ every 3 minutes. One minute's rest was given between each stage, during which a blood sample was taken from a finger tip $(25 \mu \mathrm{l})$ and transferred to $100 \mu \mathrm{l}$ of $6 \%$ perchloric acid. These samples were analysed (Analox) to evaluate blood lactic acid concentration. This was plotted against heart rate and from this graph the heart rate and percent heart rate reserve corresponding to the level of $4 \mathrm{mM}$ blood lactate were evaluated.

Maximal aerobic capacity was evaluated during the second session. The test was performed on a wheelchair rolling on a motor driven treadmill. The subjects performed a graded exercise test with a constant speed (4-5 mph) starting with $0 \%$ elavation which was increased by $1 \%$ every minute. The test continued until the subjects were exhausted.

During the third session a graded arm cycle ergometer test (ACE) was performed (Fleish cycle ergometer) with 30 watts as a starting load which was increased by 30 watts every 2 minutes. Respiratory and oxygen uptake variables were measured during the two testing sessions for the evaluation of maximal aerobic capacity by an automated metabolic cart (Medical Graphics). The following parameters were monitored at each stage: heart rate, oxygen consumption, ventilation and respiratory exchange ratio.

The metabolic cart was calibrated before each test with known primary standard quality gases. The electrocardiogram and the heart rate were continuously monitored during the testing sessions.

\section{Results}

In Table II heart rate and \% heart rate reserve values corresponding to the anaerobic threshold of $4 \mathrm{mM}$ blood lactate, while working with a wheelchair on a motor-driven treadmill, are given. The heart rate at the anaerobic threshold ranged between 115 and 168 beat $/ \mathrm{min}$, the \% heart

Table II Heart rate values corresponding to the anaerobic threshold of $4 \mathrm{mM}$ blood lactic acid while working with a wheelchair on a motor driven treadmill

\begin{tabular}{lcc}
\hline Subject & $\begin{array}{c}\text { Heart rate } \\
\text { b/min }\end{array}$ & $\begin{array}{c}\text { \% Heart rate } \\
\text { reserve }\end{array}$ \\
\hline 1 & 168 & 81.25 \\
2 & 151 & 65.59 \\
3 & 161 & 67.30 \\
4 & 125 & 62.30 \\
5 & 129 & 44.89 \\
6 & 122 & 41.05 \\
7 & 141 & 49.82 \\
8 & 115 & 43.97 \\
Mean & 139 & 57.02 \\
SD & 19.4 & 14.23 \\
\hline
\end{tabular}


rate reserve ranged between $43.97 \%$ and $81.25 \%$.

Oxygen consumption, ventilation, heart rate, and repiratory exhange ratio at maximal exercise on the arm cycle ergometer are given in Table III. Table $\mathrm{V}$ describes the same variables at peak exercise working with a wheelchair on a motor driven treadmill.

Low correlations were found between peak exercise $\mathrm{VO}_{2}$ and ventilation measured while working on a wheelchair rolling on a motor driven treadmill and those measured with and arm cycle ergometer $(r=0.57$ $p=0.137$ for $\mathrm{VO}_{2}$ and $r=0.4 p=0.233$ for $\mathrm{VE}$ ).

\section{Discussion}

One of the difficulties in evaluating the results of physical work capacity of wheelchair-dependent subjects is that they usually present a heterogenic group. Subjects usually differ in the cause of their disability and the level of disability. Veeger et $a l^{8}$ reported the aerobic capacity of a large group of wheelchair-dependent athletes in relation to their disability level according to the International Stoke Mandeville Games classification (ISMG) ${ }^{9}$ and sports discipline. Other studies used small groups, ${ }^{10.11}$ or groups with mixed levels of disability ${ }^{12.13}$ and training level. ${ }^{14-16}$ Another problem in evaluating the results of aerobic capacity of wheelchair-dependent subjects is the impor- tant effect of the ergometer used on the test results. The ergometers most often used are an arm cycle ergometer (ACE), ${ }^{3.5}$ a wheelchair ergometer (WCERG) which is usually a specially designed wheelchair ${ }^{17}$ or a regular wheelchair used on a wide motor driven treadmill. $^{8}$

Glazer et $a l^{17}$ and Wicks et $a l^{16}$ have compared physiological responses to maximal effort using WCERG and ACE. Peak $\mathrm{VO}_{2}$ and maximal ventilation were reported to be similar with both modes of exercise. ${ }^{17}$ However, physiological reponses and maximal power output were different. ${ }^{17}$ This of course is not surprising since the two exercise modes use different muscles and biomechanics. In the present investigation the exercise modes used were, working with a regular wheelchair rolling on a motor driven treadmill and arm cycle ergometry.

With the reservations mentioned above, the main finding of the present study is the low aerobic capacity of our subjects. The subjects, all being members of a competing athletic group, were expected to have a higher aerobic capacity. Maximal oxygen consumption ( $\mathrm{VO}_{2}$ max) measured by arm cycle ergometry ranged between $16.58 \mathrm{ml} /$ $\mathrm{kg} / \mathrm{min}$ and $36.24 \mathrm{ml} / \mathrm{kg} / \mathrm{min}$ with a mean of $23.1 \mathrm{ml} / \mathrm{kg} / \mathrm{min}$. Using a wheelchair on a motor driven treadmill the range for $\mathrm{VO}_{2} \mathrm{max}$ was $15.67-38.71 \mathrm{ml} / \mathrm{kg} / \mathrm{min}$ with a mean of $24.07 \mathrm{ml} / \mathrm{kg} / \mathrm{min}$. These values are much lower than those reported by Veeger et $a l^{8}$ for wheelchair-dependent basketball players. Using a wheelchair on a motor

Table III Physiological parameters at maximal exercise on the arm cycle ergometer

\begin{tabular}{lcccc}
\hline Subject & $\mathrm{VO}_{2} \mathrm{ml} / \mathrm{kg} / \mathrm{min}$ & $\mathrm{VE} \mathrm{l} / \mathrm{min}$ & $\mathrm{HR} \mathrm{b} / \mathrm{min}$ & $\mathrm{VCO}_{2} / \mathrm{VO}_{2}$ \\
\hline 1 & 18.98 & 62.9 & 191 & 1.31 \\
2 & 18.59 & 55.3 & 195 & 1.27 \\
3 & 17.08 & 71.8 & 201 & 1.22 \\
4 & 31.18 & 62.1 & 151 & 1.19 \\
5 & 36.24 & 127.7 & 183 & 1.27 \\
6 & 21.15 & 103.1 & 164 & 1.23 \\
7 & 24.94 & 91.5 & 180 & 1.16 \\
8 & 16.58 & 107.1 & 180 & 1.22 \\
Mean & 23.09 & 85.0 & 181 & 0.07 \\
SD & 7.18 & 26.0 & 16.4 &
\end{tabular}

$\mathrm{VO}_{2}=$ oxygen uptake; $\mathrm{VE}=$ minute ventilation; $\mathrm{HR}=$ heart rate; $\mathrm{R}=$ respiratory exchange ratio. 
Table IV Physiological parameters at maximal exercise working with a wheelchair on a motor driven treadmill

\begin{tabular}{lcccc}
\hline Subject & $\mathrm{VO}_{2} \mathrm{ml} / \mathrm{kg} / \mathrm{min}$ & $\mathrm{VEl} / \mathrm{min}$ & $\mathrm{HR} \mathrm{b} / \mathrm{min}$ & $\mathrm{VCO}_{2} / \mathrm{VO}_{2}$ \\
\hline 1 & 18.00 & 49.8 & 186 & 1.28 \\
2 & 17.00 & 71.3 & 183 & 1.36 \\
3 & 24.07 & 43.5 & 195 & 1.08 \\
4 & 38.71 & 13.2 & 169 & 1.43 \\
5 & 26.22 & 102.2 & 183 & 0.40 \\
6 & 15.67 & 123.0 & 178 & 1.13 \\
7 & 27.01 & 85.3 & 180 & 1.18 \\
8 & 25.91 & 129.6 & 178 & 1.22 \\
Mean & 24.07 & 92.09 & 181.5 & 0.18 \\
SD & 7.45 & 35.2 & 7.5 & \\
\hline
\end{tabular}

$\mathrm{VO}_{2}=$ oxygen uptake; $\mathrm{VE}=$ minute ventilation $; \mathrm{HR}=$ heart rate $; \mathrm{R}=$ respiratory exchange ratio.

driven treadmill they found a mean $\mathrm{VO}_{2}$ max of $37.9 \mathrm{ml} / \mathrm{kg} / \mathrm{min}$. It should be noted that the subjects in the present study were very similar in age (mean age in the present study 31.2 yrs as compared to 29 yrs in Veeger et $a l)$ and percent fat (16\% in both studies). In addition, a lower mean maximal ventilation $(92 \mathrm{l} / \mathrm{min})$ was reached by our subjects as compared to $122.8 \mathrm{l} / \mathrm{min}$ reported by Veeger et al. ${ }^{8}$

Maximal heart rate and respiratory exchange ratio $(\mathrm{R})$ did not differ significantly between the present study and Veeger's study. ${ }^{8}$ Coutts \& Stogryn ${ }^{10}$ tested six wheelchair-depenent track and field athletes using a special wheelchair ergometer. They reported a $\mathrm{VO}_{2}$ max in the range of $16.9-$ $50.7 \mathrm{ml} / \mathrm{kg} / \mathrm{min}$ with a mean of $33 \mathrm{ml} /$ $\mathrm{kg} / \mathrm{min}$.

According to Kofsky et al ${ }^{18}$ our subjects would be classified as having average aerobic capacity as nonathletes. As athletes, they would be classified as having a low aerobic capacity. Thus, the subjects in the present investigation may be described as recreationally active wheelchair-dependent basketball players rather than true representatives of elite wheelchair-dependent athletes. This also fits their training volume which usually included only two basketball training session per week, one game and one strength training session per week.

Few studies have reported values for the anaerobic threshold in wheelchair-depend- ent subjects. Lakomy et $a l^{15}$ reported the wheelchair velocity coresponding to $4 \mathrm{mM}$ blood lactate concentration and found a correlation of $0.83-0.87$ between this speed and the performance of a $5 \mathrm{~km}$ race. They also estimated the $\% \mathrm{VO}_{2}$ max being utilised during the $5 \mathrm{~km}$ test to be in the range of $61 \%$ to $95 \%$.

Aigner et $a l^{19}$ reported wheelchair velocity and heart rate at 3 and $4 \mathrm{mM}$ blood lactate for some of their subjects. They found a good correlation $(r=0.91)$ between the heart rate corresponding to $4 \mathrm{mM}$ blood lactic acid and the calculated heart rate at $80 \%$ of heart rate reserve. In the present study the percent heart rate reserve corresponding to $4 \mathrm{mM}$ blood lactate was found to be significantly lower. Mean percent heart rate reserve in our subjects was $57 \%$ with a range of $41 \%$ to $81.2 \%$.

In view of the importance of the anaerobic threshold for the evaluation and the prediction of aerobic performance 20.21 more studies are needed to create norms of anaerobic threshold for wheelchair-dependent subjects. Another aspect of the present study is the comparison between physiological responses at peak exercise working with an arm cycle ergometer as compared to a wheelchair on a motor driven treadmill.

In the present study low correlations were found between peak exercise $\mathrm{VO}_{2}$ and minute ventilation measured while working with an arm cycle ergometer and those measured with a wheelchair on a motor 
driven treadmill. ( $r=0.57, p=0.137$ for $\mathrm{VO}_{2}$ and $r=0.4, p=0.233$ for minute ventilation). However, Glaser et $a l^{17}$ and Wicks et $a^{16}$ reported a high correlation between $\mathrm{VO}_{2} \max$, maximal ventilation and heart rate measured with an arm cycle ergometer and those measured by a special wheelchair ergometer.

A possible explanation for our different results may be the fact that in the present study each subject used his own personal wheelchair on a motor driven treadmill while in the other studies ${ }^{16,17}$ the same specially designed wheelchair ergometer was used by all the subjects.

A further possible explanation for the different results is that by using a wheelchair on a motor driven treadmill extra energy may be needed to keep a straight course of propulsion as well as to stabilise the trunk at higher elevations of the treadmill. In addition, it may be possible that the low correlations between values measured with the arm cycle ergometer and the wheelchair on a motor driven treadmill is the result of the fact that in the present study a fixed arm crank height was used that could not be adjusted to subjects' shoulder height in order to enable maximal efficiency for all the subjects.

Thus, although it seems that, according to the studies of Glaser et $a l^{17}$ and Wicks et $a l,{ }^{16}$ either exercise mode may be used for the evaluation of aerobic capacity in the disabled, it is very clear that the protocol used and the ergometer type may have a significant effect on the measured values.

This is especialy true when testing wheelchair-dependent subjects. Thus, in the evaluation of physical work capacity of wheelchair-dependent subjects great care should be taken in choosing the ergometer and adjusting it to the subjects' dimensions. Standardised and internationally accepted exercise protocols for the evaluation of physical work capacity of wheelchairdependent subjects are needed to enable an efficient comparison of training methods and to establish fitness norms for wheelchair-dependent athletes.

\section{References}

1 Peizer E, Freiberger H, Wright D (1964) Bioengineering methods of wheelchair evaluation. Bull Prosthet Res 10: 19-37.

2 Hildenbrandt G, Voigt ED, Berendes B, Kroeger J (1970) Energy cost of propelling wheelchair at various speeds: Cardiac responses and effect on steering accuracy. Arch Phys Med Rehabil 51: 131-136.

3 Zwirn LD, Bar-Or O (1975) Responses to exercise of paraplegics who differ in conditioning level. Med Sci Sports Exerc 7: 94-98.

4 Yekutiel M, Brooks EM, Ohry A, Jarom J, Carel R (1983) The relevance of hypertension, ischemic heart disease and diabetes in traumatic spinal cord injured patients and amputees. Paraplegia 27: 58-62.

5 Hjeltnes N (1980) Control of medical rehabilitation of para- and tetraplegics. In Natvig H, editor. The First International Congress on Sports for the Disabled. Royal Ministry of Church and Education, Oslo: 162-173.

6 Jochheim KA, Strohkendl H (1978) The value of particular sports of the wheelchair disabled in maintaining health of the paraplegic. Paraplegia 11: 173-178.

7 Steadward R, Walsh L (1986) Training and fitness programs for disabled athletes: past, present and future. In Sherril E, editor. Sport and Disabled Athletes. Human kinetics, Champaign, Ill: 3-20.

8 Veeger HEJ, Hadj Yahmed M, Van der Woude LHV, Charpentier P (1991) Peak oxygen uptake and maximal power output of olympic wheelchair-dependent athletes. Med Sci Sports Exerc 23: 1201-1209.

9 McCann, BC (1984) Classification of locomotor disabled for competitive sports: theory and practice. Int J Sports Med 5: 167-170.

10 Coutts KD, Stogryn JL (1987) Aerobic and anaerobic power of Canadian wheelchair track athletes. Med Sci Sports Exerc 19: 62-65.

11 Crews D, Wells LC, Burkett L, Mckeeman V (1982) A physiological profile of four wheelchair marathon racers. Physic Sports Med 10: 134-143.

12 Gass GC, Camp EM (1984) The maximum physiological responses during incremental wheelchair and arm cranking exercise in male paraplegic. Med Sci Sports Exerc 16: 355-359.

13 Miles DS, Sawka MN, Wilde SW, Durbin RJ Gotshall W, Glaser RM (1982) Pulmonary function changes in wheelchair athletes subsequent to exercise training. Ergonomics 25: 239-246.

14 Huellemann KD, List M, Matthes D, Wiese G, Zika D (1975) Spiroergometric and telemetric investigations during the XXI International Stoke Mandeville Games 1972 in Heidelberg. Paraplegia 13: 109-123.

15 Lakomy HKA, Campbell I, Williams C (1987) Treadmill performance and selected physiological characteristics of wheelchair athletes. Br J Sports Med 21: 130-133. 
16 Wicks JR Lymburner K, Dinsdale SM, Jones NL (1977-1978) The use of multistage exercise testing with wheelchair ergometry and arm cranking in subjects with spinal cord lesions. Paraplegia 15: 252-261.

17 Glaser RM, Sawka MN, Brune MF, Wilde SW (1980) Physiological responses to maximal effort wheelchair and arm crank ergometry. J Appl Phyiol: Respirat Environ Exer Physiol 48: 1060-1064.

18 Kofsky PR, Shepard RJ Davis GM, Jackson RW (1986) Fitness classification tables for lower-limb disabled individuals. In: Sherrill C, editor. Sport and Disabled Athletes. Human Kinetics, Champaign, Ill: 147-155.

19 Aigner A, Muss N, Pfaller W (1990) Die anerobe Schwelle von Rollstuhlsportlern. Dt Z F Sportrmed 41: $312-315$.

20 Farrell PA, Wilmore JH, Coyle EF, Costill DL (1979) Plasma lactate accumulation and distance running performance. Med Sci Sports 11: 338-344.

21 Sjodin B, Jacobs I (1981) Onset of blood lactate accumulation and marathon running performance. Int $J$ Sports Med 2: 23-26. 